\title{
POPULAÇÃO NEGRA, EDUCAÇÃO E MUDANÇA INSTITUCIONAL
}

\author{
Tatiana Dias Silva ${ }^{1}$
}

Resumo: O objetivo deste texto é analisar alguns impasses sobre a situação educacional da população negra, notadamente sobre acesso à educação formal e alfabetização. Além da trajetória dos indicadores, procurou-se refletir sobre impasses no nível institucional, que têm dificultado a implementação mais radical dos inúmeros avanços conquistados no domínio estrutural. Para tanto, a reflexão serve-se da análise de Collins (2000) sobre domínios de poder, concentrando nos limites impostos e oportunidades de enfrentamento a partir do domínio disciplinar, em uma matriz que estrutura as relações de opressão baseadas em raça. Assim, acredita-se contribuir com uma agenda de pesquisa e de ação, que pode em muito beneficiar as disputas em torno de uma sociedade e uma administração pública com menos desigualdades raciais.

Palavras-chave: Raça; População Negra; Educação; Desigualdades Raciais.

\section{BLACK POPULATION, EDUCATION AND INSTITUTIONAL CHANGE}

Abstract: The purpose of this text is to analyze some impasses about the educational situation of the black population, especially about the access to formal education and literacy. Besides the trajectory of the figures, we reflect on impasses on the institutional level, which have hampered a more radical implementation of the many advances that were achieved in the structural domain. In order to do so, the reflection is based on Collins' (2000) analysis of domains of power, concentrating on the imposed limits and opportunities of confrontation from the disciplinary domain in a matrix that structures race-based relations of oppression. Thus, it might contribute with a research and action agenda, which can greatly benefit the disputes around a society and a public administration with less racial inequalities.

Key-words: Race; Black Population; Education; Racial Inequalities.

\section{POPULATION NOIRE, ÉDUCATION ET CHANGEMIENT INSTITUTIONNEL}

Résumé: Le objectif de ce texte est d'analyser certaines impasses sur la situation de la population noire en matière d'éducation, spécialement sur l'accès à l'éducation formelle et à l'alphabétisation. Outre la trajectoire des indicateurs, on avons cherché à réfléchir sur les impasses au niveau institutionnel, qui ont empêché la mise en œuvre plus radicale des nombreux progrès réalisés dans le domaine structurel. Pour ce faire, la réflexion s'appuie sur l'analyse des domaines du pouvoir effectuée par Collins (2000), en se concentrant sur les limites imposées et les opportunités de confrontation dans le domaine disciplinaire, dans une matrice qui structure les relations d'oppression fondées sur la race. Ainsi, on pense qu'elle contribue avec un programme de recherche et d'action, ce qui peut grandement profiter aux conflits autour d'une société et d'une administration publique moins accusées d'inégalités raciales. Mots-clés: race, population noire, éducation, inégalités raciales.

1 Doutoranda em Administração pela Universidade de Brasília, mestra em Administração pela Universidade Federal da Bahia. Técnica de Planejamento e Pesquisa do Instituto de Pesquisa Econômica Aplicada.E-mail: tatiana.silva@ipea.gov.br

Revista da ABPN • v. 11, Ed. Especial - Caderno Temático: Raça Negra e Educação 30 anos depois: e agora, do que mais precisamos falar? • abril de 2019, p.163-175 
Mots-clés: Race; Population Noire; Éducation; Inégalités Raciales.

\section{POBLACIÓN NEGRA, EDUCACIÓN Y CAMIBIO INSTITUCIONAL}

Resumen: El objetivo de este texto es analizar algunos impasses sobre la situación educativa de la población negra, especialmente sobre el acceso a la educación formal y la alfabetización. Además de la trayectoria de los indicadores, se intentó reflexionar sobre impasses a nivel institucional, que han dificultado la aplicación más radical de los innumerables avances conquistados en el dominio estructural. Para esto, la reflexión se sirve del análisis de Collins (2000) sobre dominios de poder, concentrándose en los límites impuestos y oportunidades de enfrentamiento a partir del dominio disciplinario, en una matriz que estructura las relaciones de opresión basadas en raza. Así, se cree contribuir con una agenda de investigación y de acción, que puede en mucho beneficiar a las disputas en torno a una sociedad y una administración pública con menos desigualdades raciales.

Palabras-claves: Raza; Población Negra; Educación; Desigualdades Raciales.

Em 1987, o periódico Cadernos de Pesquisa, publicado pela Fundação Carlos Chagas, divulgou um dossiê elaborado a partir do Seminário: "O Negro e a Educação", ocorrido em 1986. Um dos documentos presentes nessa coletânea é o texto de Carlos Hasenbalg, intitulado "Desigualdades sociais e oportunidade educacional". Nesse artigo, instigado por pesquisa sobre a situação educacional de negros no estado de São Paulo, o autor destaca importantes impasses em torno do tema do negro na educação, a seguir transcritos:

$\mathrm{O}$ negro ingressa ou não ingressa no sistema formal de ensino?; $\mathrm{O}$ negro consegue vencer a barreira da $1^{\text {a }}$ série do primeiro grau, enfim, consegue se alfabetizar ou não?; O negro consegue completar as quatro primeiras séries do $1^{\circ}$ grau, o antigo primário? (Hasenbalg, 1987, p. 24)

As questões são formuladas em torno do acesso e sucesso escolar nas primeiras etapas da educação básica. Decerto, hoje, muitos outros questionamentos podem ser adicionados, sem que estes, formulados às vésperas da promulgação da Constituição de 1988 , tenham sido plenamente superados.

Embora o acesso aos níveis iniciais do ensino fundamental tenha atingido patamares próximos à universalização, e tendo a questão do acesso, em geral, se deslocado notadamente para o ensino superior, é impressionante que o desafio da alfabetização e das desigualdades raciais no sucesso escolar estejam ainda tão presentes no Brasil.

Diversos autores e autoras têm oferecido uma excelente contribuição para a reflexão sobre as desigualdades raciais na educação, por meio de análises e pesquisas 
sobre o racismo na educação, educação antirracista (Filice, 2011; Jesus; Gomes, 2013; Gomes, 2012), movimento negro e educação (Santos, 2014), educação quilombola (Miranda, 2012; MourA, 2011), dados estatísticos educacionais (IPEA et al., 2011; Paixão; Rossetto, 2012; Senkevics; Machado; Oliveira, 2016), ação afirmativa no ensino superior (Santos, 2014; Carvalho, INCTI, 2012; GEMAA s.d.), ampliando os horizontes do debate empreendido na década de 1980 e incluindo também considerações sobre as ações efetivamente implementadas desde então.

O objetivo deste texto é mais modesto, concentrando-se na atualização dos impasses sobre acesso e alfabetização apontados por Hasenbalg em 1987. Nesse sentido, além de séries históricas que evidenciam avanços e desafios na fruição do direito à educação no Brasil, por brancos e negros, pretende-se propor um debate sobre impasses de outra ordem: os impasses institucionais. Entendendo-se instituições como regras formais e informais, a interpretação que é dada a elas e a expectativa social de comportamento dos atores (Streeck; Thelen, 2005), em adição a essa perspectiva, procura-se beneficiar da lente analítica de Patrícia Hill Collins (2000), no que chama de matriz de dominação, para ampliar a compreensão sobre a natureza desses obstáculos.

Para tanto, este texto se desdobra em mais três seções. Na seguinte, procura-se apresentar a trajetória de indicadores sobre educação relativos a acesso e a alfabetização. Na terceira seção, expõe-se a matriz de dominação de Hill Collins e, por fim, apresentam-se considerações finais sobre os impasses identificados e os limites institucionais que têm constrangido um maior progresso na redução das desigualdades raciais.

\section{POPULAÇÃO NEGRA E EDUCAÇÃO: DO ACESSO E DA ALFABETIZAÇÃO}

A taxa de frequência líquida é um dos principais indicadores de acesso. Mais do que retratar o contingente populacional que frequenta determinada etapa de ensino, esse indicador mostra quem o faz na idade considerada adequada. Assim, 6 a 14 anos é a faixa etária considerada adequada para cursar o ensino fundamental; 15 a 17, o ensino médio; e 18 a 24, o ensino superior (nos dados a serem apresentados, pós-graduação strictu sensu inclusive).

A Figura 1 mostra a trajetória desses indicadores. Contrastando dados dos últimos 20 anos, verifica-se que o acesso ao ensino fundamental está praticamente 
universalizado para ambos os grupos raciais. Embora cerca de $80,8 \%$ da população negra acessasse o ensino fundamental na idade adequada em 1995 ao passo que a taxa para as crianças brancas era de 90,2\%, em 2015 os indicadores estão praticamente igualados. A observação, está claro, restringe-se ao acesso. A despeito da relevância, não se questiona aqui qualidade da escola, rendimento ou sucesso escolar.

As desigualdades de acesso acentuam-se fortemente à medida que as oportunidades se reduzem. É o caso do ensino médio, cuja taxa para brancos é de 64,6\% e, para os negros, pouco ultrapassa a metade da população nessa faixa etária (52\%). No entanto, importa destacar que houve significativa redução das desigualdades, uma vez que a taxa atual da população negra representa $80,5 \%$ da taxa da população branca nessa etapa, ao passo que essa relação era de apenas 37,3\% há duas décadas.

Na educação superior, por sua vez, em 1995, de cada 100 negros entre 18 a 24 anos, apenas dois frequentavam o ensino superior ou pós-graduação strictu sensu (em contraste com 9 brancos a cada 100). O acesso era restrito para ambos os grupos, mas não é pequena a desigualdade racial mesmo nesse cenário. Em 2015, após os inegáveis avanços de uma década de ações afirmativas e de ampliação das matrículas no ensino superior (INCTI, 2012 ou Carvalho, 2012; GEMAA, s.d.), a frequência líquida dos negros nessa etapa ainda é menor do que a taxa já usufruída pela população branca no início deste século ${ }^{2}$.

2 Frequência líquida ensino superior 2015: negros, 12,5\%; brancos, 25\%. Frequência líquida ensino superior 2001: negros, 3,2\%; brancos, $14,1 \%$ 


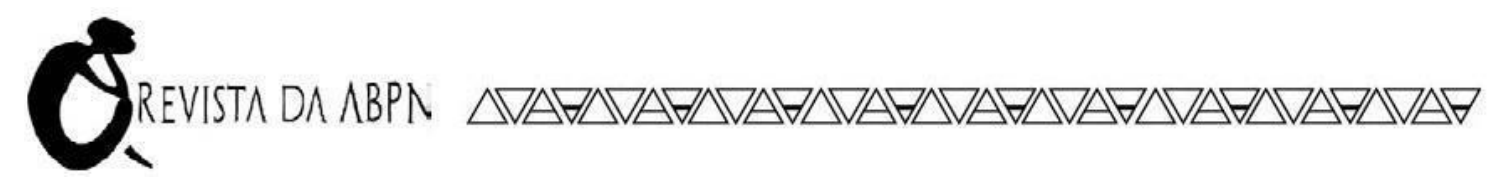

Figura 1. Taxa de frequência líquida segundo cor. Brasil, 1995 a 2015
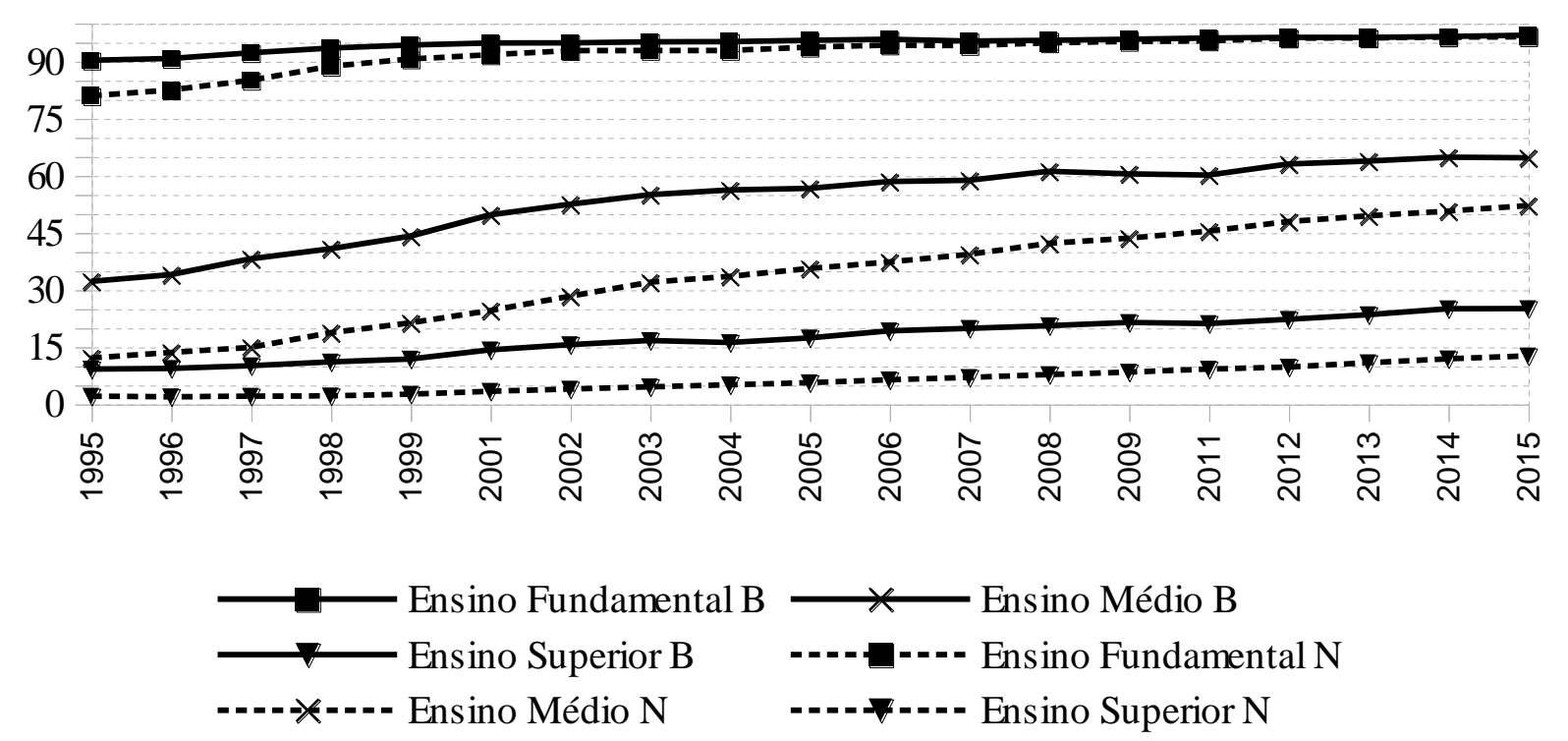

Fonte: Elaboração própria, com base nos dados do Ipea e ONU Mulheres, SPM e SEPPIR $(2015)^{3}$. (N: negros; B: brancos).

Um outro impasse a ser analisado é o problema do analfabetismo. Decerto, houve expressiva redução do analfabetismo ao longo das duas décadas em análise. Passou-se de um contingente de $15,5 \%$ da população para $8 \%$ nesse interstício. No entanto, nesse quesito, diferente dos anteriores, não se pode comemorar uma significativa redução das desigualdades entre brancos e negros.

A Figura 2 mostra a trajetória da taxa de analfabetismo, considerando a taxa de negros, brancos e a taxa total, além da razão entre as distintas taxas. Trata-se da linha pontilhada, que exprime a razão entre a taxa da população negra e a da população

\footnotetext{
3 “A Pnad não foi realizada nos anos de 2000 e 2010. Em 2004, a Pnad passa a contemplar a população rural de Rondônia, Acre, Amazonas, Roraima, Pará e Amapá. Em 2007, a duração do ensino fundamental passa a ser de nove anos, tal como disposto na Lei $\mathrm{n}^{\circ} 11.274 / 2006$, e as crianças de seis anos passaram a ser incorporadas ao $1^{\circ}$ ano do ensino fundamental. Os municípios, estados e o Distrito Federal tiveram prazo até 2010 para adaptar-se a essa nova realidade. A taxa de escolarização líquida fornece a proporção da população matriculada no nível de ensino considerado adequado conforme a faixa etária. Até 2006 foram consideradas as seguintes faixas etárias: educação básica para crianças com até 6 anos ( 0 a 6 anos); ensino fundamental de 7 a 14 anos; ensino médio de 15 a 17 anos e ensino superior de 18 a 24 anos. A partir de 2007, as faixas etárias da educação básica e ensino fundamental sofrem alteração devido a Lei $\mathrm{n}^{\circ}$ 11.274/2006. A educação básica para crianças com até 5 anos ( 0 a 5 anos); ensino fundamental de 6 a 14 anos; sendo que as crianças de 6 anos não que estavam cursando o ensino fundamental com 9 anos de duração foram contabilizadas no nível educação básica. A população negra é composta por pretos e pardos." (IPEA; ONU Mulheres, 2011).
} 
branca. Pode-se verificar que a redução é praticamente nula. Se, em 1995, a taxa de analfabetismo entre os negros era 2,5 vezes a taxa entre a população branca, essa razão, em 20 anos, regrediu apenas 0,3 pontos. Ou seja, mesmo em nível tão básico e apesar da expressiva melhoria nos níveis de alfabetização da população, a situação entre brancos e negros praticamente não se alterou. E o mais gritante é que, apesar de se tratar de requisito tão elementar, o sistema educacional continua produzindo analfabetos e desigualdade racial entre eles. Em 2012, a taxa de analfabetismo era de 1,2\% para os negros e 0,5\% para os brancos de 15 a 17 anos. Entre os jovens de 25 a 29 anos, ainda tínhamos 3,8\% analfabetos entre os negros e 1,5\% entre os brancos (Matijascic; Silva, 2016).

\section{Figura 2. Taxa de analfabetismo da população de 15 anos ou mais de idade, segundo cor. Brasil, 1995 a 2015}
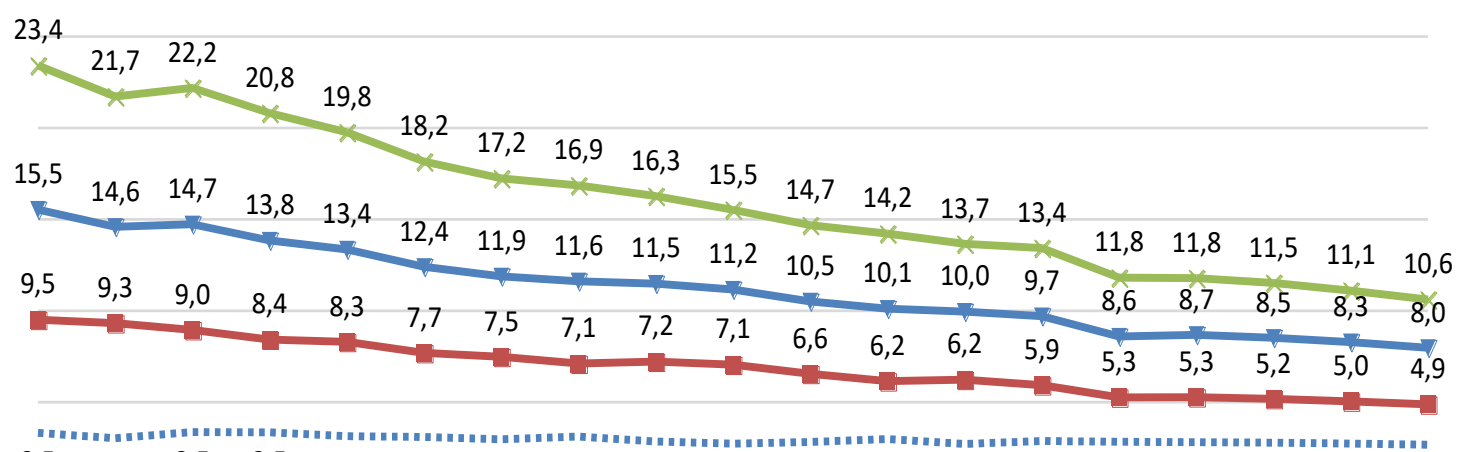

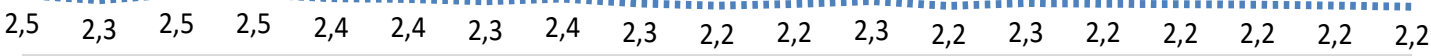

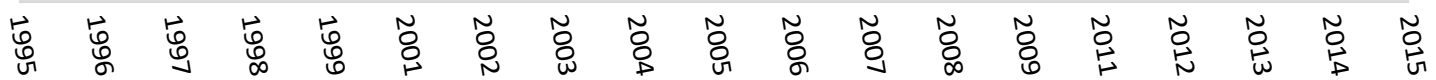

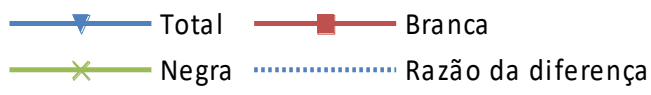

Fonte: Elaboração própria, com base nos dados do Ipea e Onu Mulheres, SPM e SEPPIR(2015) ${ }^{4}$

Grosso modo, ainda que os dados mostrem um cenário de melhorias tanto para a educação de modo geral como para redução das desigualdades raciais, os impasses mais gerais a que se referem os questionamentos de Hasenbalg ainda não estão superados. Após décadas de gradual avanço no debate sobre relações raciais no país, que culminou

\footnotetext{
4"A taxa de analfabetismo é o quociente da divisão do total de pessoas, nas categorias selecionadas, que não sabem ler ou escrever pela população total em tal categoria” (IPEA; ONU Mulheres, SPM e SEPPIR 2011).
} 
com conquistas legislativas, como a Constituição Federal de 1988, leis de combate à discriminação racial e o Estatuto da Igualdade Racial, com a implementação vigorosa da política de cotas no ensino superior e, paralelamente, no serviço público - inicialmente de forma autônoma pelas universidades e entes subnacionais e posteriormente pelo governo federal -, uma sociedade racialmente menos desigual ainda parece um cenário longínquo. Decerto, o enfrentamento das desigualdades raciais na educação não se dá apenas em base setorial; trata-se, antes de tudo, de enfrentar as condições impostas pelo racismo institucional, considerado como mecanismo estrutural que promove $\mathrm{o}$ tratamento diferenciado a grupos raciais subordinados, garantindo a produção e reprodução de uma determinada hierarquia social (Werneck, s.d.).

A seção seguinte busca contribuir com algumas reflexões sobre a natureza das barreiras a serem enfrentadas para alcance de um cenário com mais equidade entre os diferentes grupos raciais.

\section{MUDANÇA INSTITUCIONAL: DIÁLOGOS COM OS DOMÍNIOS DE PODER}

Collins (2000) compreende que, a despeito das resistências individuais ou grupais contra o racismo, é possível identificar um modo mais estruturado de opressão e ação. Para enfrentar centralmente o racismo e a desigualdade racial, seria necessário se apropriar desse arcabouço, ou seja, conhecer para combater. Essa estrutura de opressão é o que a autora denomina de matriz de dominação, em que são articuladas interseccionalidades de raça, gênero, origem, sexualidade, classe e a conjugação dos domínios de poder.

A partir de uma combinação entre eixos de dominação (raça, gênero, classe, sexualidade e origem) e domínios de poder (estrutural, interpessoal, disciplinar e hegemônico), é possível analisar de modo mais complexo a realidade do que apenas focar na lógica opressor e oprimido. De fato, segundo essa abordagem, não haveria opressores nem oprimidos em estado puro. O mesmo indivíduo pode se encontrar em uma situação de vulnerabilidade, por um lado, e atuar como algoz, por outro lado, considerada a multiplicidade de combinações possível nessa matriz.

Considerando, neste ensaio, especialmente a questão racial, as desvantagens sociais promovidas por essa condição poderiam ser mapeadas nos quatro domínios 
identificados. Cabe ressaltar que Collins $(2000,2016)$ escreve a partir da perspectiva do feminismo negro, de origem norte-americana, que se consolida na segunda metade do século XX, por meio de uma literatura multidisciplinar e um debate autônomo tanto em relação ao feminismo de maioria branca como ao movimento negro (Collins, 2016). Os domínios de poder são dirigidos, na sua análise, às mulheres negras, mas ampliado para homens e mulheres negras, em uma busca mais ampla por justiça social.

O domínio estrutural diz respeito a como as instituições, ainda que independentemente, mas de forma sistêmica, reproduzem um padrão de desigualdades baseado em raça. Esse domínio refere-se ao nível institucional, a como as organizações estão estruturadas para reproduzir o racismo e pode ser considerado em linha com o conceito de racismo institucional expresso anteriormente. Mesmo iniciativas neutras em relação à raça seriam promotoras de desigualdade, ao não considerar as diferenças entre os beneficiários, excluindo parcela considerável de seu escopo, ou não considerando as limitações de acesso e usufruto dos serviços.

No domínio disciplinar, é considerado o papel da supervisão burocrática, tanto para gerenciar as relações de poder dentro das organizações e o papel destacado para os indivíduos negros como para "minar" as políticas voltadas à promoção da igualdade racial. Nesse domínio, uma vez que não se poderia mais apenas excluir os grupos raciais, a autora identifica o papel das burocracias em controlar e moldar o comportamento dos seus integrantes, estabelecendo padrões de ocupação de hierarquias, papéis e formas de acesso às políticas públicas (estigmatização do pobre, rotinas extenuantes como fonte de poder da burocracia) (Collins, 2000). Enquanto o domínio estrutural refere-se às instituições, o domínio disciplinar relaciona-se à sua operação.

Por sua vez, o domínio hegemônico do poder refere-se à ideologia, cultura e consciência, que procura justificar as práticas dos domínios precedentes, por meio de visões compartilhadas em variados espaços de reprodução social. Funciona como uma conexão entre as instituições (domínio estrutural), práticas organizacionais (domínio disciplinar) e interação social (domínio interpessoal). Por fim, no domínio interpessoal, estão as práticas rotineiras e cotidianas de relacionamento. Trata-se do nível micro da organização social, em que também múltiplas estratégias individuais de resistência são forjadas. 
Ainda que elaborada no contexto norte-americano e voltado para o empoderamento das mulheres negras, a matriz de dominação constitui amplo quadro explicativo dos mecanismos de dominação de raça e gênero. Como o próprio feminismo negro se propõe a ser projeto de justiça social ampla, procura-se utilizar esse framework para analisar as opressões raciais e medidas para seu enfrentamento no quadro das políticas públicas brasileiras recentes.

Neste texto, a maior atenção é dada ao domínio disciplinar. Apesar das inúmeras conquistas no domínio estrutural, que vão desde a criação de estruturas governamentais até a aprovação de diversas leis e ordenamentos que avançam na promoção da igualdade racial (lei das cotas, estatuto da igualdade racial), muitas dessas normas não são amplamente ou eficazmente implementadas (Jesus; Gomes, 2013; Filice, 2011; Silva et al., 2011). De fato, a política precisa constantemente se reafirmar, contar com a sensibilidade dos agentes que deveriam implementá-la (Reinach, 2013). Gomes e Jesus (2013) analisam a implementação da obrigatoriedade do ensino da história da África, cultura afro-brasileira e do negro no Brasil, estabelecida na Lei n. 10.639/2003 (Gomes e Jesus, 2013). Identificam diferentes níveis de enraizamento da proposta, com predominância do esforço individual, além de falta de formação de professores, de recursos necessários e de intolerância religiosa, que limita o êxito da política. Em análise sobre a implementação de cotas no serviço público, Volpe e Silva (2016) apontam resistência ao tema e inúmeros conflitos na implementação, ainda que, na maioria das experiências, a aprovação legislativa não tenha encontrado muitas dificuldades. Reinach (2013), em análise sobre a transversalidade em políticas públicas, identifica o percurso árduo de gestores de políticas de igualdade racial em fazer valer as políticas e diretrizes instituídas.

Embora o enfretamento ao racismo e, notadamente, as políticas de promoção da igualdade racial tenham obtido progresso relevante nas últimas décadas, essa mudança recente não conseguiu superar o histórico de desigualdades e indiferença que marcam o imaginário social a partir do mito da democracia racial. Apenas recentemente o governo brasileiro passa a reconhecer o racismo como um problema e depois como um problema que merece atenção das políticas públicas. Não dista muito o tempo em que a questão racial foi excluída do censo demográfico, em um contexto de negação do problema racial (Jaccoud et al., 2009). 
No domínio disciplinar, uma série de crenças arraigadas enfrentam explícita ou implicitamente os avanços estruturais em prol da igualdade racial, tais como uma suposta meritocracia ou universalidade das políticas públicas. A desconstrução desse domínio de saber/poder (Foucault, 1979) passa por diversas estratégias, em parte, muito voltadas para a burocracia.

Uma delas pode ser sintetizada no arcabouço da burocracia representativa, que se refere à representação passiva, quando o quadro de funcionários da administração pública espelha a diversidade populacional, e à representação ativa, que passa pela atuação dos servidores em favor dos grupos minoritários a que pertençam (Kennedy, 2013). Nesse contexto, uma via de mudança seria a ocupação de lugares dentro dessa burocracia. Esse olhar de dentro permite ressignificar muitas normas e sistemas e promover, em sua medida, mudanças em torno de uma proposta mais justa. A simples presença de corpos negros na ocupação de espaços de privilégio já é um ato político. Levantar questionamento sobre a naturalizada sub-representação dos negros, problematizar políticas públicas sob um enfoque que envolva diferentes públicos, por si só, já são grandes passos para ampliar e efetivar os avanços no domínio estrutural. Por essa razão, a proposta de cotas no serviço público parece muito mais alvissareira que seu valor de face, como também o são as ações afirmativas no ensino superior.

Uma outra perspectiva de ação nesse domínio refere-se à apropriação dos códigos e normas da gestão pública. A meu ver, há ainda limitada participação das organizações do movimento negro e acadêmicos na análise sobre a gestão das políticas de igualdade racial, em termos das políticas de orçamento e planejamento, mecanismos de implementação e avaliação, entre outras abordagens. Em levantamento sobre a temática racial em periódicos de administração pública, nacionais e internacionais, entre 2011 a maio de 2016, Silva (2016) localizou apenas 56 artigos em 30 periódicos. Entre esses, apenas 22 artigos provinham de periódicos nacionais, a despeito da grande ampliação do debate público sobre ações afirmativas e políticas de igualdade racial. Nesses textos, todavia, o foco majoritário era dado às políticas de cotas para ingresso na universidade, o que sinaliza lacunas importantes para avanço na reflexão sobre as recentes políticas nacionais de igualdade racial, uma vez que outros tipos de ação afirmativa, políticas de combate ao racismo, gestão de políticas de igualdade racial, educação antirracista, quilombos ou ainda sobre transversalidade e raça, parecem estar 
negligenciados na comunidade de administração pública no país.

\section{CONSIDERAÇÕES FINAIS}

Este texto é decorrência da minha participação no seminário Raça Negra e Educação 30 anos depois: e agora do que mais precisamos falar?, promovido em agosto de 2017, pelo Núcleo de Estudos Afro-brasileiros da Universidade Federal de São Paulo (NEAB/Unifesp), Fundação Carlos Chagas (FCC) e Associação Brasileira de Pesquisadores/as Negros/as (ABPN).

Nessa ocasião, o objetivo da minha exposição foi debater sobre a situação do negro no sistema de educação na atualidade, a partir da perspectiva dos impasses apresentados no debate anterior, de 30 anos atrás, e consolidada no texto de Hasenbalg. A partir de dados estatísticos sobre participação do negro na educação formal, com destaque para níveis até mesmo elementares, como a alfabetização, verificou-se que os avanços foram significativos, mas muitos impasses permanecem, ainda que a análise tenha se limitado a essas categorias de informação. Com efeito, muitas outras categorias de impasses nesse campo poderiam ser acrescentadas e foram abordadas por outros participantes ao longo do seminário.

No entanto, para além da trajetória dos indicadores, procurou-se refletir sobre impasses no nível institucional, que têm dificultado a implementação mais radical dos inúmeros avanços conquistados no domínio estrutural. Para tanto, a reflexão serve-se da análise de Collins (2000) sobre domínios de poder, concentrando nos limites impostos e oportunidades de enfrentamento a partir da dimensão disciplinar que estrutura as relações de opressão baseadas em raça. Assim, acredita-se contribuir com uma agenda de pesquisa e de ação que pode em muito beneficiar as disputas em torno de uma sociedade e uma administração pública com menos desigualdades raciais.

\section{REFERÊNCIAS}

COLLINS, Patricia Hill. Black Feminist Thought: knowledge, consciousness, and politics of empowerment. New York/London: Routledge, 2000.

COLLINS, Patricia Hill. Aprendendo com a outsider within: a significação sociológica do pensamento feminista negro. Sociedade e Estado, v. 31, n. 1, p. 99-127, 2016.

FILICE, R. C. G. Raça e classe na gestão da educação básica brasileira: a cultura na

Revista da ABPN • v. 11, Ed. Especial - Caderno Temático: Raça Negra e Educação 30 anos depois: e agora, do que mais precisamos falar? • abril de 2019, p.163-175

DOI 10.31418/2177-2770.2019.v11.c.1.p163-175 
implementação de políticas públicas. Campinas: Autores Associados, 2011.

FOUCAULT, Michel. Microfisica do poder. Rio de Janeiro: Graal, 1979. 29. reimpressão.

GEMAA. Grupo de Estudos Multidisciplinares das Ação Afirmativa. Mapa das ações afirmativas. Rio de Janeiro: IESP; UERJ, [s.d.]. Disponível em: $<$ http://gemaa.iesp.uerj.br/mapa-da-acao-afirmativa/>. Acesso em 20 out. 2017.

GOMES, N. L. (Org.). Práticas pedagógicas de trabalho com relações etnicorraciais na escola na perspectiva da Lei no 10.639/03. Brasília: MEC; Unesco, 2012.

HASENBALG, Carlos A. Desigualdades sociais e oportunidade educacional. Cadernos de Pesquisa, São Paulo, n. 63, p. 24-26, 1987.

CARVALHO, J. J. (Org.). Mapa das ações afirmativas no Brasil. Brasília: INCTI, 2012

IPEA, ONU Mulheres, Secretaria de Políticas para as mulheres, Secretaria de Políticas de Promovação da Igualdade Racial. Indicadores. Retrato das desigualdades de gênero e raça. 2015. Disponível em: <www.ipea.gov.br/retrato. Acesso em: 20 out. 2017.

IPEA; ONU Mulheres, Secretaria de Políticas para as mulheres. Retrato das desigualdades de gênero e raça. 4. ed. Brasília: Ipea; ONU Mulheres, 2011.

IPEA; ONU Mulheres, Secretaria de Políticas para as Mulheres (SPM), Secretaria de Políticas de Promoção da Igualdade Racial (Seppir). Retrato das desigualdades de gênero e raça. 4. ed. Disponível em: http://www.ipea.gov.br/retrato/pdf/revista.pdf. Acesso em 01 ago 2017. Brasília: Ipea; ONU Mulheres, 2011. 39 p.

JACCOUD, Luciana; SILVA, Adailton; ROSA, Waldemir; LUIZ, Cristiana. Entre o racismo e a desigualdade: da constituição à promoção de uma política de igualdade racial (1988-2008). Políticas Sociais - acompanhamento e análise, n. 17, p 261-327, 2009. (Vinte Anos da Constituição Federal, v. 3).

JESUS, Rodrigo E.; GOMES, Nilma L. Panorama de implementação da lei n. 10.639/2003: contribuições da pesquisa práticas pedagógicas de trabalho com relações étnico-raciais na escola. In: SILVA, Tatiana D.prenome?; GOES, Fernanda (Org.). Igualdade racial no Brasil: reflexões no Ano Internacional dos Afrodescendentes. Brasília: Ipea, 2013. P 81-96.

KENNEDY, Brandy A. Sorting Through: The Role of Representation in Bureaucracy. J Public Adm Res Theory, v. 23, n. 4, p. 791-816, 2013. doi: 10.1093/jopart/mut028.

MATIJASCIC, Milko. SILVA, Tatiana D. Jovens negros: panorama da situação social no Brasil segundo indicadores selecionados entre 1992 e 2012. In: SILVA, Enid R. A.; BOTELHO, Rosana U. (Org.). Dimensões da experiência juvenil brasileira e novos desafios às políticas públicas. Brasília: Ipea, 2016. P 269-291?

MIRANDA, Shirley A. de. Educação escolar quilombola em Minas Gerais: entre ausências e emergências. Revista Brasileira de Educação, v. 17, n. 50, p 369-383, maio/ago. 2012.

MOURA, Maria da Glória. Texto-referência para a elaboração das Diretrizes Curriculares Nacionais para a Educação Escolar Quilombola. Brasília: Conselho Nacional de Educação, Câmara da Educação Básica, 2011. 
PAIXÃO, Marcelo; ROSSETTO, Irene. Levantamento das fontes de dados estatísticos sobre a variável cor ou raça no Brasil contemporâneo: terminologias classificatórias, qualidade das bases de dados e implicações para as políticas públicas [online]. In: ENCONTRO ANUAL DA ANPOCS, 36, Águas de Lindoia (SP), 21-25/out./2012. Anais... Águas de Lindoia (SP): ANPOCS, 2012.

REINACH, Sofia. Gestão transversal das políticas públicas no âmbito federal: uma leitura inicial. Dissertação (Mestrado em Administração Pública e Governo) - FGV - Fundação Getúlio Vargas, São Paulo, 2013.

SANTOS, Sales A. dos. Educação: um pensamento negro contemporâneo. Jundiaí: Paco Editorial, 2014.

SENKEVICS, Adriano Souza; MACHADO, Taís de Sant'Anna; OLIVEIRA; Adolfo Samuel de. A cor ou raça nas estatísticas educacionais: uma análise dos instrumentos de pesquisa do Inep. Brasília: Inep, 2016.

SILVA, Tatiana D. Administração pública e relações raciais: uma análise da produção científica entre 2011 e 2016. In: ENCONTRO DE ADMINISTRAÇÃO PÚBLICA E GOVERNANÇA, VII, 2016. Anais... São Paulo: Anpad, 2016.

SILVA, T. et al. Planejamento e financiamento das políticas de igualdade racial: possibilidades para o plano plurianual 2012-2015. Nota técnica Disoc n. 7. Brasília: Ipea, 2011.

STREECK, Wolfgang; THELEN, Kathleen. Introduction: institutional change in advanced political economies. In: STREECK, Wolfgang; THELEN, Kathleen. (Ed.). Beyond continuity: institutional change and advanced political economies. New York: Oxford University Press, 2005. P 1-39.

VOLPE, Ana Paula; SILVA, Tatiana Dias. Reserva de vagas para negros na administração pública. Relatório de Pesquisa. Brasília: Ipea, 2016.

WERNECK, Jurema. Racismo institucional: uma abordagem conceitual. Geledés - Instituto da Mulher Negra; Cfemea - Centro Feminista de Estudos e Assessoria (Coord.) [s.d assessoria. s.d.] 